\title{
The Role of Course Evaluation and Needs Analyses for Syllabus Design: An Application to "English Language" Course for Master-Degree Students in Economics
}

\author{
Ismagilova L.R. a \\ Polyakova O.V. ${ }^{\mathrm{b}}$ \\ a b Kazan Federal University, Kazan, 420008, Russia \\ Email: oks182@mail.ru
}

Doi:10.5901/mjss.2015.v6n1s3p346

\section{Abstract}

The article considers the adjustment of the course design process to the new education paradigm. The transition to the competence approach imposed by the New Standards of Higher Education requires fresh perspective to syllabus construction and implies flexibility to be used by course designers. The authors highlight the importance of amalgam of formative and summative assessments, needs analysis and pre- and post-course evaluation to be mandatory instruments to this end. The experiment conducted by the researchers proves the need of balanced and broad-based approach to the syllabus design that would lead to better performance and greater learners' satisfaction. Some recommendations are submitted for approval to the $\mathrm{HEl}$ authorities as a practical outcome of the experiment.

Keywords: syllabus design, competence approach, needs analysis, course evaluation, formative assessment, summative assessment

\section{Introduction}

The transformation of system of Higher Education in the Russian Federation in recent years has set certain challenges to those who are involved in the process of teaching and curriculum development. The introduction of New Standards of Higher Education has shifted the education paradigm from skills centered to learning centered. [Gorelova, 2014] The new reality both in the sphere of education and in the working environment that graduates will face after getting the Degree forced HEl authorities to develop certain framework for course development. This framework will allow State Education Authorities to control the final result according to the set of competences imposed by the Standard.

As far as English language ability is concerned the Standard requires Master-Degree students to have it at the level that will allow successful professional communication [Baklashova, 2014]. To meet the requirements of the Standard and to follow the learning-centered approach needs analyses and course evaluation are crucial. The syllabus that was developed by the Foreign Languages Department for Economics, Business and Finance sets the following objectives to be achieved while taking the "English language" course:

- To master the ability to understand various texts in the field of the professional interest.

- To develop the ability to use language flexibly and effectively for social, academic and professional purposes.

- To develop the ability to use language as a means of oral and written communication for professional and academic purposes.

- To form the ability to maintain life-long learning as a means of professional and personal development [Ismagilova and Polyakova, 2014].

The course is divided into six inter-related modules that are all aimed at mastering language for science abilities:

1. Text organization and the structure of the article;

2. Summaries and effective reading;

3. Critical reading and writing;

4. Writing an academic essay;

5. Written presentations;

6. Presentations and debates [Ismagilova and Polyakova, 2014].

Materials selected for each module are based on broad spectrum of professional interests that graduates may show enthusiasm to research and encourage academic and professional development [Galishnikova, 2014].

The main objective of the article is to prove the significance of needs analyses and pre- and post-course evaluation 
to achieve the required level of English language proficiency maintaining the desired level of learners satisfaction which does not prevent from successful learning process [Kudryavtseva, 2014].

\section{Theory}

The importance of the needs analyses for Syllabus design is an indisputable issue. It acts as terminus a quo for materials selection, assessment criteria and activities that the course will be based on. Many articles were published about this problem by [Alderson, 1980, Berwick, 1989, Brindley, 1989, Crocker, 1981, Hawkey, 1980, Robinson, 1983].

As for needs analyses definition it could vary but it will be based on the learner as the central part of the analyses anyway.

Widdowson [Widdowson, 1983] distinguishes "goal-oriented" and "process-oriented" definition of needs. The key feature of this approach is the importance to evaluate the present language ability of the learner and to recognize the target situation where the learner will use the language. The "goal-oriented" definition is correlated to the objectives set while designing the syllabus whereas the "process-oriented" definition relates to pedagogic aims.

Hutchinson and Waters [Hutchinson and Waters, 1987] make a distinction between "target needs" and "learning needs". The target need refers to what the learner needs to do in the target situation and the learning need refers to what the learner needs to do in order to learn. They further subcategorize target need into (1) necessities; what the learner has to know in order to function effectively in the target situation, (2) lacks; the discrepancy between necessity and what the learner already knows, (3) wants; what the learner actually wants to learn or what they feel they need. The learner's "wants" may or may not conform to those perceived by the teachers or course designers. The learning need is equated to the route of learning. This concerns things such as how learners learn the language, why they learn it, what resources are available to help them learn.

Altman [Altman, 1980] focuses on types of learner needs that are derived from individual differences within learnercentered language teaching framework. According to Altman, learners should be placed properly based on their age, level of language proficiency, maturity and time available. This condition requires institutions to have flexible educational arrangements to provide all learners full access to courses that are appropriate according to their needs. Thus, the content and mode of learning will be influenced by the options available. The types of modifications of learning resources are made accordingly to meet the individual differences with regard to time, goals, mode, or expectations of learning.

Although needs analyses should be considered as the initial stage for designing the course, changes concerning learner needs may be made during the course with regard to the learners. Having obtained information about learner needs a course designer will be able to produce a specification of language skills, methods of teaching and class activities to meet them.

McDonough [McDonough, 1984] states that the language needs of the learner should be the bases for course development. He says "information on his or her language needs will help in drawing up a profile to establish coherent objectives, and take subsequent decisions on course content".

As for course evaluation some scholars divide it into two levels: learner assessment and course evaluation.

Learner assessment is considered to be a strategic point at the beginning and at the end of the course. Following this perception there are three basic types of assessment: placement tests, achievement tests and proficiency tests.

Course evaluation helps to identify how successfully course objectives were met and what amendments to the course the designer should introduce to achieve better results in the future.

Alderson and Waters point out four main aspects to consider while developing course evaluation programme:

- What should be evaluated?

- How can the course be evaluated?

- Who should be involved in evaluation?

- When (and how often) should evaluation take place?

The final stage could be further divided into implicit evaluation - takes place during the course, and explicit - takes place at the end of the course. Direct Observation technique is one of the ways to identify the level of learners' satisfaction with the way material is presented, the success learners make and the difficulties that arise. "The course Questionnaire" and "Course Forum" are the options to conduct explicit evaluation. The Questionnaire should be organized in such a way to stimulate the willingness of the responders to give full and thoughtful answers and the Forum allows for anonymity, perhaps eliciting more genuine responses. The ultimate objective of all these methods is to receive learners' attitude towards the subject matter, instructional methods, activities and teacher's role in the course. 


\section{Method}

To prove the significance of thorough needs analyses and proper pre- and post-course evaluation the authors of this article set an experiment. Out of all Master-Degree graduates one group of learners was chosen as a reference group where all types of analyses and evaluation were implemented. Both formative and summative assessment was conducted.

The goal of formative assessment was to monitor student learning to provide ongoing feedback that could be used by instructors to improve their teaching and by students to improve their learning. The goal of summative assessment was to evaluate student learning at the end of an instructional unit by comparing it against the Standard.

The total number of the students taking Master-Degree was 105 graduates. The reference group comprises 12 post-graduates.

To conduct a thorough needs analysis questionnaires and informal discussions with learners were held before the course. During the course learners' performance was assessed via assignments of different types, a final project as a form of summative assessment was analyzed after the course. This combination of pre-course, mid-course and postcourse analyses was conducted in order to see the progress and the gaps of the students throughout this course. The accumulated results were used as a feedback to be further used as a basis for introducing the following year's course amendments.

\section{Results}

The questionnaires that were used as a pre-course needs analysis produced large amount of information about learners. Interpreting Three Section Pre-Course Evaluation Report the following results were obtained:

Section 1: What do you need English for?

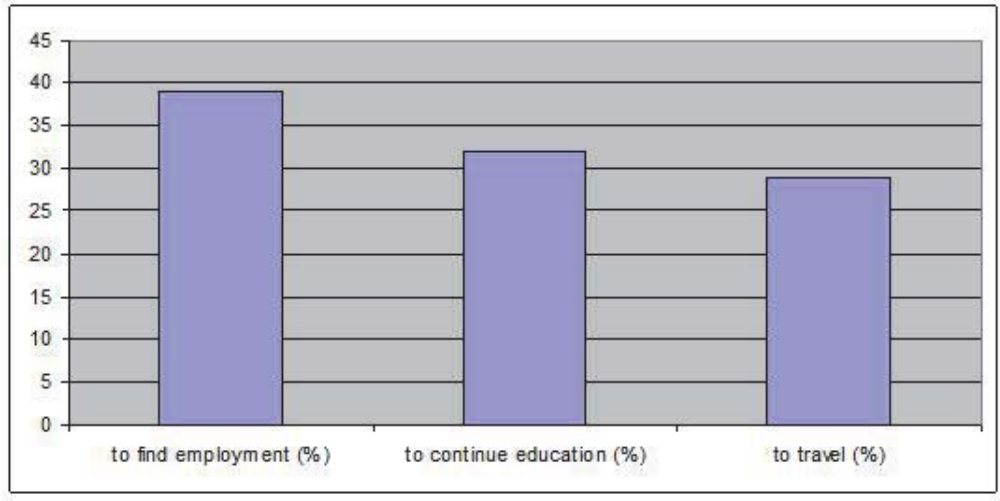

Section 2: What do you expect from this course?

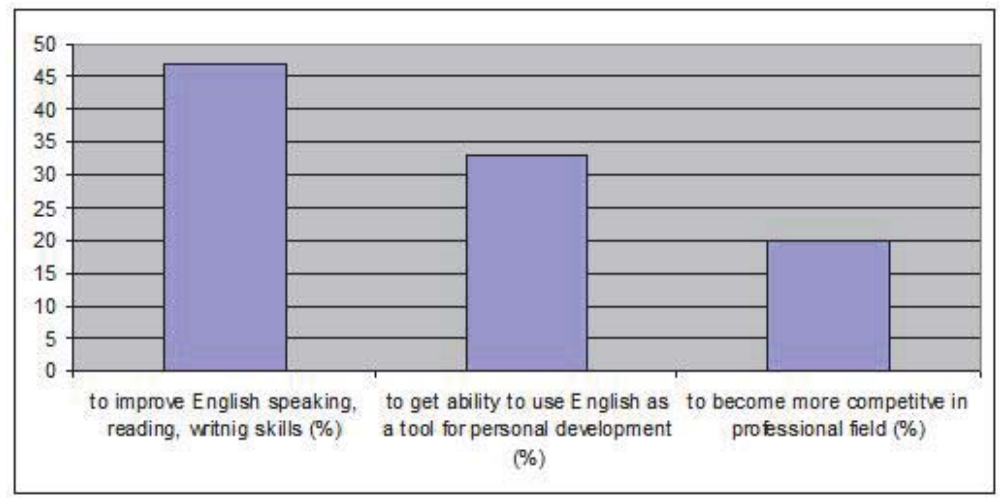


Section 3: How do you want this course to be organised?

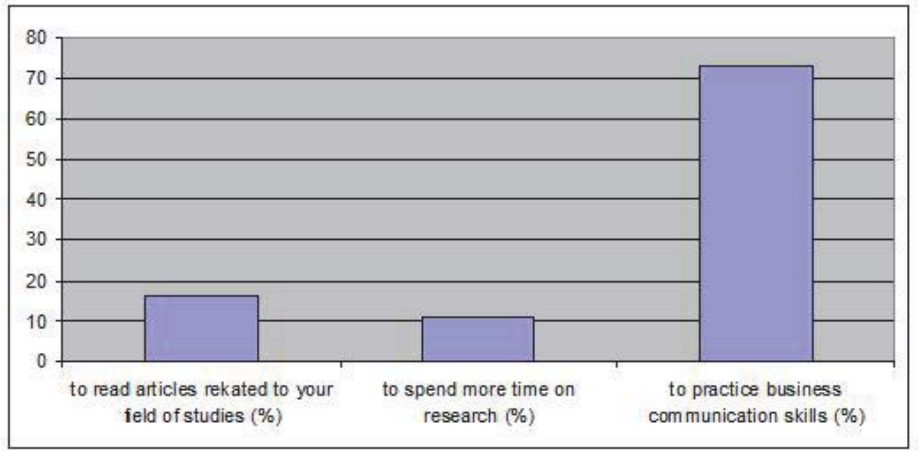

Pre-Course Evaluation Report clearly showed that learners' needs, expectations and desired classroom activities were not exactly the same as the developers of the course initially contemplated. In particular $73 \%$ of the learners expected the course to be Business English training rather than English for Science which did not match the objectives of the course. On the other hand, $40 \%$ wanted to find the job after improvement of English language level, but only $20 \%$ saw language as a tool to become more competitive in the professional field. It could happen partly due to lack of preparatory sessions to the programme and partly due to low level of English language ability showed by the graduates [Mardanshina and Zhuravleva, 2014]. Moreover, informal discussion that allowed getting ideas and thoughts spontaneously showed that students wanted to get Business English course rather then English for Academic Purposes as it was set in the curriculum.

In the reference group the results of the Pre-Course Evaluation Report were the following:

Section 1: What do you need English for?

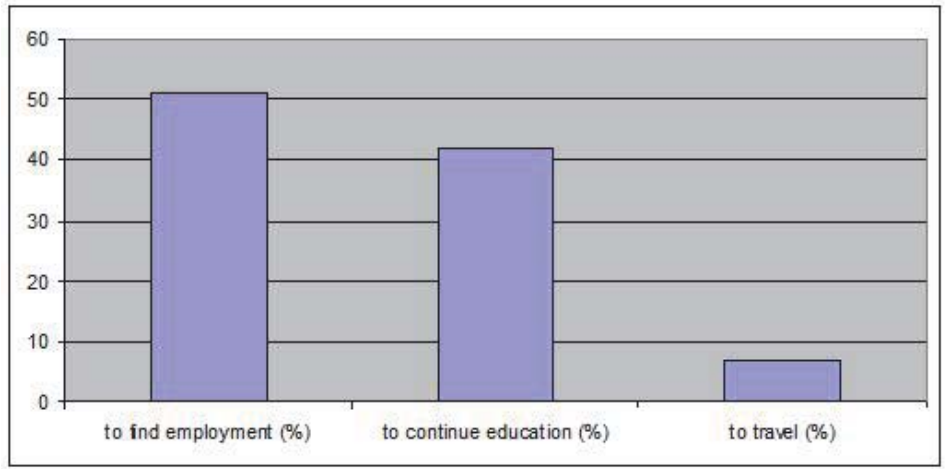

Section 2: What do you expect from this course?

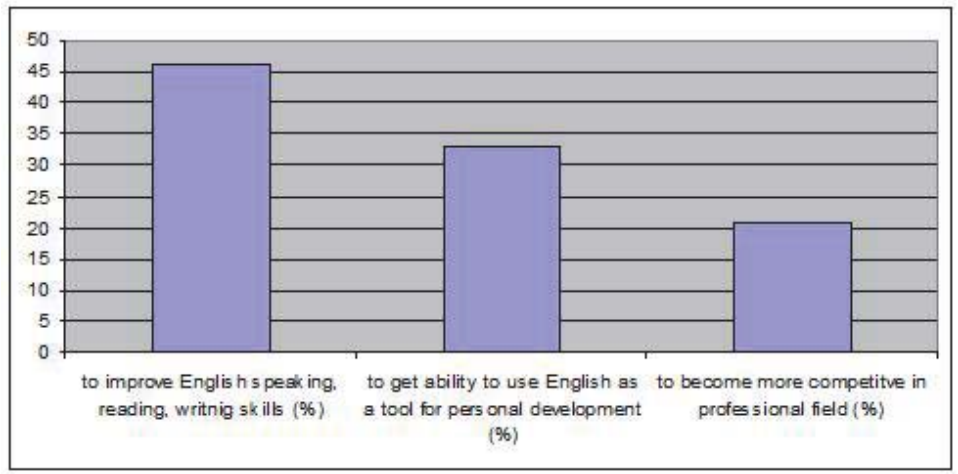


Section 3: How do you want this course to be organized?

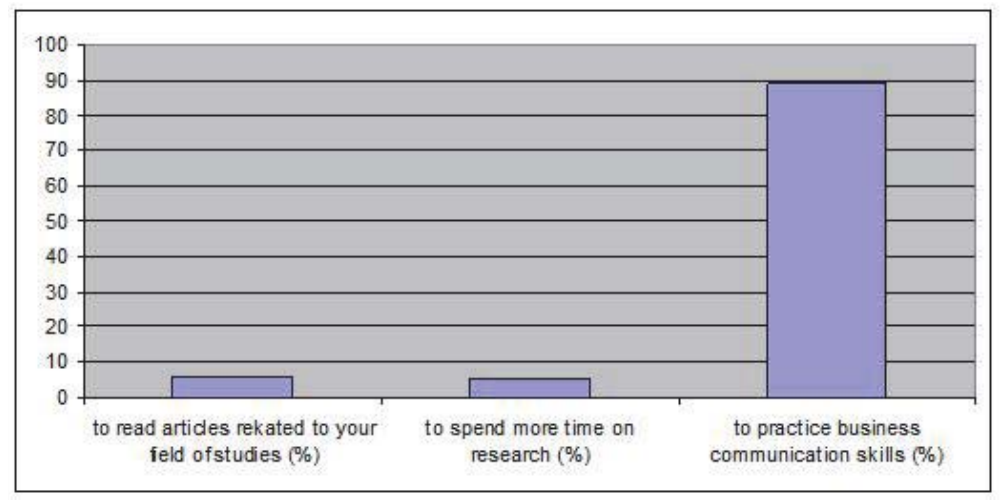

The results of the reference group were more impressive. Only $5 \%$ were ready to devote time to the research whereas $89 \%$ expected to practice Business communication skills. Nearly half of them wanted to improve their English language skills to find well-paid job. Around $40 \%$ wanted to continue education and $33 \%$ were planning to develop personally with the help of the course. The obtained data convinced the designers to introduce some changes to the original course to make it more flexible and integrated. Each module was altered and some Business communication activities were added. Mid-course needs analysis was an effective tool to assess learners' performance. Assignments during the course were used as a means to ascertain real problems during this course. The mid-term project demonstrated that learners in the reference group showed better performance and higher level of satisfaction from the learning process than those excluded from the experiment.

Final assessment results (total)

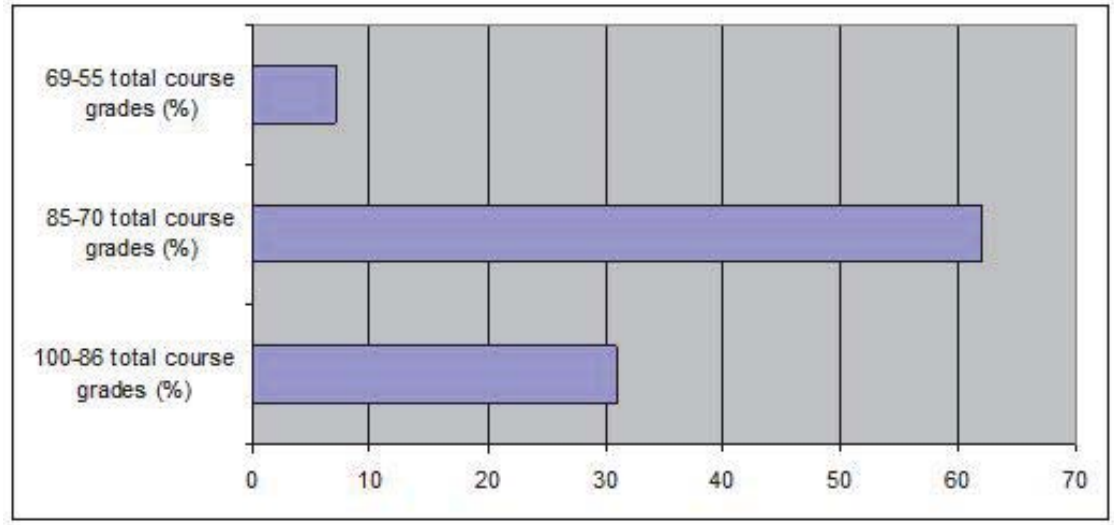

Final assessment results (reference group)

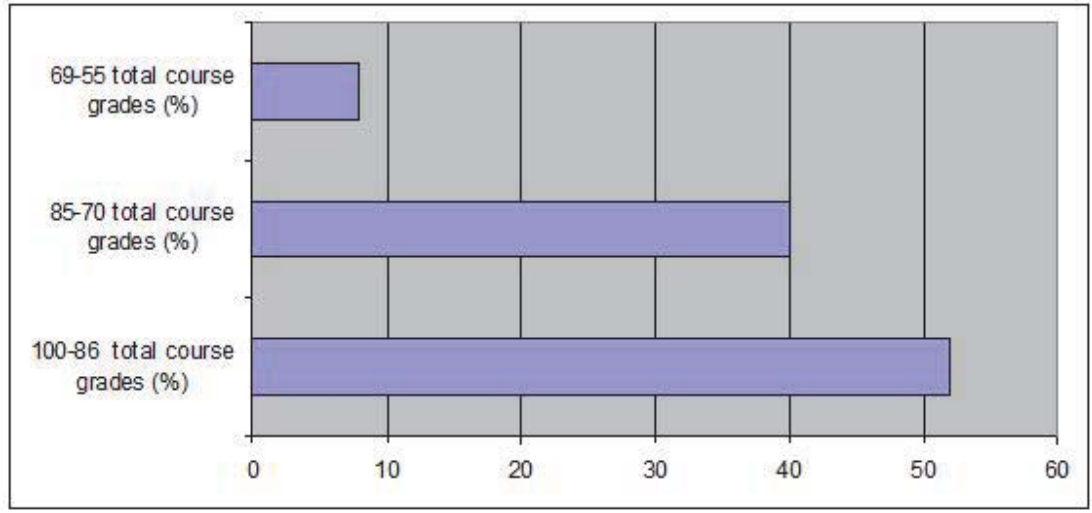


After analysing the feedback from the post-course needs analysis the final project results hypothesis of the research was proven. The fact that less than $10 \%$ of the learners showed low results justifies the approach chosen by the researchers. However, only a third of all post-graduates out of total number could accomplish the tasks at a high level performance while over half of the reference group projects were better structured and delivered due to the adjustments made throughout the course which led to higher level of motivation and self-appreciation [Zalyaeva and Solodkova, 2014].

\section{Conclusion}

The results of the experiment conducted by the authors clearly showed that both needs analyses and course evaluation are indispensible aspects of syllabus design. To improve the quality of education process and to achieve better final assessment results the following recommendations were developed and introduced to the HEl authorities:

- For more successful learning process it is necessary to organize English language entry test for those who apply for Master-Degree programme.

- Pre-course training session will help graduates to get a better understanding of the course objectives and will increase motivation [Grigorieva, 2014].

- English for Business Purposes training added to the curriculum will lead to increase the awareness about the content of the Master-Degree programme in general and English language course in particular.

The amalgam of these measures will encourage graduates to spend more time on research and it will result in greater scientific input made by them to the HEl.

\section{References}

Alderson, J.C. A Process Approach to Reading at The University of Mexico Projects in materials design. ELT Documents Special, 1980

Altman, H. B. Foreign Language Teaching: Focus on The Learner. In H.B. Altman \& C.V. James (eds.), Foreign Language Teaching: Meeting Individual Needs. New York: Pergamon Press, 1980

Baklashova,T. Manager's Professional Training in Russia: Syllabus and Technologies // Procedia - Social and Behavioral Sciences. Vol. 152, 2014. pp.1057-1061

Berwick, R. Needs Assessment iii Language Programming: from Theory to Practice. In R.K. Johnson (ed.), The Second Language Curriculum. New York: Cambridge University Press, 1989.

Brindley, C. The Role of Needs Analysis in Adult ESL Programme Design. In R.K. Johnson (ed), The Second Language Curriculum. New York: Cambridge University Press, 1989

Crocker, T. Scenes of Endless Science: ESP and Education. The ESP Teacher: Role, Development and Prospects. ELT Documents 112. London: The British Council, 1981

Galishnikova, E. Language Learning Motivation: A Look at the Additional Program // Procedia - Social and Behavioral Sciences. Vol. 152, 2014. pp.1137-1142

Gorelova, J. Advertising Language as a Means of Forming Students' Cross-cultural Competence // Procedia - Social and Behavioral Sciences. Vol. 152, 2014. pp. 668-672

Grigorieva, E. Language Teaching Content Renovation in the Context of Higher Education Internationalization // Procedia - Social and Behavioral Sciences. Vol. 152, 2014. pp.1143-1147

Hawkey, R. Syllabus Design for Specific Purposes. ELT Documents Special. Projects in Materials Design. London: The British Council, 1980.

Hutchinson \& Waters. English for Specific Purposes. New York: Cambridge University Press, 1987

McDonough, J. ESP in Perspective: A Practical Guide. London: Jo McDonough, 1984

Robinson, P. ESP Today. New York: Cambridge University Press, 1991.

Widdowson, H.G. Learning Purpose and Language Use. New York: Oxford University Press, 1983

Zalyaeva, E., Solodkova, I. // Teacher-student Collaboration: Institute of Economics and Finance Kazan Federal University Approach // Procedia - Social and Behavioral Sciences. Vol. 152, 2014. pp.1039-1044 